\title{
Interview with Nadia Nurhussein Black Land: Imperial Ethiopianism in African America
}

\author{
Adom Getachew*
}

In October 2020, Adom Getachew interviewed Nadia Nurhussein about her recent book "Black Land: Imperial Ethiopianism and African America" published by Princeton University Press in 2019. Black Land delves into nineteenth- and twentieth-century African American artistic and journalistic depictions of Ethiopia, illuminating the increasing tensions and ironies behind cultural celebrations of an African country asserting itself as an imperial power. Nurhussein navigates texts by Walt Whitman, Paul Laurence Dunbar, Pauline Hopkins, Harry Dean, Langston Hughes, Claude McKay, George Schuyler, and others, alongside images and performances that show the intersection of African America with Ethiopia during historic political shifts. From a description of a notorious 1920 Star Order of Ethiopia flag-burning demonstration in Chicago to a discussion of the Ethiopian emperor Haile Selassie as Time magazine's Man of the Year for 1935, Nurhussein illuminates the growing complications that modern Ethiopia posed for American writers and activists who wrestled with Pan-African ideal and the reality of Ethiopia as an imperialist state. Black Land was Winner of the MSA Book Prize, from the Modernist Studies Association, finalist for the Pauli Murray Book Prize from the African American Intellectual History Society and shortlisted for the MAAH Stone Book Award from the Museum of African American History.

$$
* * *
$$

DOI: https://dx.doi.org/10.4314/ejossah.v17i1.7

\footnotetext{
*Neubauer Family Assistant professor, Department of Political Science, University of Chicago, Email: agetachew@uchicago.edu, Tel.: (773) 834-8723, Chicago/ Illinois
}

This work is licensed to the publisher under the Creative Commons Attribution-NonCommercialNoDerivs License. 


\section{Adom Getachew}

Adom Getachew (AG): Thanks so much for agreeing to talk with me about your recent book Black Land where you chart a specific kind of Ethiopianism that flourished between the late 19th and early 20th century. And I wonder if we can just start by you giving us a sense of what makes this period and this moment of Ethiopianism different from the long history of identification with Ethiopia, and versions of Ethiopianism that flourished in the long 19th century.

Nadia Nurhussein (NN): Sure. My focus is on literature and the thing that I started to notice about the literature being written in the late 19th century is that there was much more of an engagement with the actual country known as Abyssinia, and that the current events and history, which were much more widely known, informed how creative writers were understanding Ethiopianism. The sort of more abstract ideology with its biblical basis seemed to me like it was becoming much more historically informed and much more concrete. I talk in the first chapter of my book about how, for example, poems by Walt Whitman and Paul Laurence Dunbar, and a few lesser known writers, were either addressing directly historical military events or writing in a way that, to me, suggested that they were aware of those events.

$A G$ : I actually wanted to ask about where you start. We are doing this interview in part on the occasion of the 125th anniversary of the battle of Adwa in 1896 and the journal "Ethiopian Journal of the Social Sciences and Humanities" where this interview is going to appear in marking that occasion. That obviously is a watershed moment, but one of the things I found really interesting and striking about where your story starts is that you slightly decenter 1896 by focusing first on a lesser known moment, the Anglo Abyssinian War of 1867. So I wondered why you decided to start there, and if you could give us a little sense of these early engagements. Whitman, Dunbar, as well as Charlotte Pendleton and E. Davidson are all engaged with this war. What did these early kind of engagements reveal about this wider practice that you call imperial Ethiopianism?

$N N$ : I wanted to talk a little bit about the Anglo Abyssinian War and, as you say, decenter the battle of Adwa, which becomes the middle military event in the book, between the Anglo Abyssinian War and the 1930s Italian invasion. For me, the Anglo Abyssinian War seemed to be a moment when media attention to Abyssinia dramatically increased because there was much more global circulation of periodicals at the time than there had been earlier. I thought that there was more of 
a chance for American writers to be familiar with what was happening between Great Britain and Abyssinia. And, furthermore, it seemed, because of Tewodros' attempts to begin consolidating the empire, that it was an important turning point in Abyssinian history for me to focus on. That's why I wanted to see how American and British writers were thinking about Tewodros and how he was engaging with the world.

$A G$ : One thing I found really interesting about this chapter and especially Whitman's poetry and Dunbar's poetry, is how the engagement with Ethiopia is also filtered through domestic concerns and anxieties. So in Whitman the civil war and the aftermath of the civil war, in Dunbar's case, we are in the nadir period in African American history. I just wanted to ask you about how Ethiopia becomes a vector or vehicle, through which authors actually end up engaging their domestic contexts in different kinds of ways?

$N N$ : Dunbar's poems, the ones that I focused on, were written in the $1890 \mathrm{~s}$, but before the battle of Adwa. As much as I wanted to think about his poems through that lens, it was not chronologically possible that he could have been thinking of the battle of Adwa. I think that it was illuminating for me to think about how ... How can I put this? To see what Abyssinia could offer African America at that particular time when there was this absolute devastation of the hopes of reconstruction. I don't think it's an accident that he would write a poem like ""Ode to Ethiopia"' at that moment. It seemed to me like it made perfect sense. And then in the case of Whitman, I think he's somebody who, as I talked about in the chapter, was very interested in doing research on different parts of the world. He was very familiar with Abyssinia. I think that he was not just seeing it as this distant country, but trying to make these connections between the US and other places in the world. And so for him, my argument was that he was seeing this character of Ethiopia, the older woman in the poem, as an equal force in the world. Equal to the US but oppositional, in a manner that strangely resembled the Confederacy in the context of the US Civil War.

$A G$ : You have already mentioned this, but there are three inflection points in the book, 1867, 1896 and 1935. All of these center around moments of war and conflict between Ethiopia and European empires. And so there is a way that war, and in particular inter-imperial war, is the vehicle through which Ethiopia is cognizable to African America. I wanted to now ask more specifically about 1896, 
and the battle of Adwa, which also coincides with a domestic crisis for AfricanAmericans in the U.S.. The Plessy v. Ferguson Supreme Court casing sanctioning segregation through the "separate but equal doctrine" occurs in the same year. I wanted to ask how the Ethiopian victory on the battlefield was depicted in African American print culture. And what are the ways the story of Ethiopian victory gets mobilized by African American authors?

$N N$ : Yeah. It was an extremely important moment. You see, for example, in African American newspapers, the coverage of the battle and this pride associated with the fact that a black nation has defeated a white nation. And as several critics have written, it was clearly perceived as a kind of refutation of white supremacy. A lot of critics have used the word "humiliation" to talk about Italy's defeat, as this completely inconceivable (for the rest of the world) victory by what was seen by a lot of people as an unprepared and barbaric nation. I think for African America and black people all over the world, it seemed like a kind of proof-evidence of the folly of white supremacy, essentially. I looked at the coincidence of the fact that it happened to be the same year as Plessy v Ferguson as something that was very generative for not just writers, but historical actors.

For example, the Star Order of Ethiopia. The members of this organization essentially looked at the relationship between the US and Ethiopia, that diplomatic relations were emerging in the beginning of the 20th century, and looked at the mobility that Ethiopians in America were afforded and said, "This is a reason why we do not pledge allegiance to the US. We are not afforded the same dignity as other black people. Why is that?" I think it is obvious that people were looking at the example of Ethiopia and thinking about how it applies to black people in the United States.

AG: A through line throughout your book, is how this form of attachment is a really complex and complicated one. So even though 1896, and the battle represents an anti-imperial moment where a black nation defeats a white nation, it is also, as you note, a moment of imperial consolidation and centralization within Ethiopia itself. And a moment that still reverberates in Ethiopian politics today as a mark of imperial expansion and centralization. And it seems to me one argument you are making throughout the book is that this imperial character of Ethiopia is a central paradox of Ethiopianism. But you also show that Ethiopia's imperial character is not simply incidental to the kinds of attachments that are facilitated by Ethiopianism. The imperial character of Ethiopia is actually the thing that draws 
people to Ethiopia as an ideal site of solidarity and identification. What makes the imperial character of Ethiopia particularly alluring or attractive to some of the figures you write about in this period?

$N N$ : That's a good question. I think the response to Imperial Ethiopia can't be divorced from the experience of being black in the United States. And especially at that particular moment - in the late 19th century, early 20th century-if you are not being allowed or afforded dignity, what is more dignified than being a King? I mean, there's something appealing about what I call the "regalization fantasy," this idea that you could be somehow connected to royalty or become royalty yourself. I think it's easy to see how that would be appealing to pretty much anybody because, even if you don't really think of yourself as a monarchist, there's an attraction to pomp and circumstance and all of that. So that's the kind of superficial way of looking at it. But I think, in addition, there's a kind of attraction to the structures of imperial culture too. I mean, to the hierarchies. It sounds contradictory, but for the writers in my chapter on martial Ethiopianism, for example - those who are writing poems celebrating militarism - there's something attractive about being part of this kind of organization, this organization of a Black empire. So I do think both impulses are coexisting: On the one hand, there is this impulse toward a hierarchical black empire and, on the other hand, there is a more egalitarian black internationalism. Both are coexisting at this time and this version of Ethiopianism is illustrating that.

$A G$ : I really loved all the moments that the regalization fantasy gets mobilized. And I want to ask some questions about it later. But before we get there, I wanted to ask about some ways to think about this contradiction. I feel like there may be two ways, or at least two ways that I thought about how one might react to the centrality of empire and imperial hierarchy in this form of attachment. I think one would be a more skeptical or critical perspective of black nationalists' solidarities, which might say something like the way that hierarchy shows up here is just one indication of the ways that forms of black nationalism or black internationalism always smuggle in forms of hierarchy, whether those hierarchies are class, gender, or imperial as in this case. And then maybe a more sympathetic view of this form of attachment which would be that in this moment of late 19th and early 20th centuries, opposition to empire, not just for black people around the world, but really anywhere around the world, has not yet taken on the form of a wider rejection of empire as such that what people are trying to do is think about ways in 
Adom Getachew

which colored empires, whether that is Ethiopian imperialism or Japanese imperialism, could be the counterpoint to white empire. It's an anti-imperial imperialism of some kind. So I just wanted to ask how you would situate your own thinking about the question of Imperial Ethiopianism.

$N N$ : No, I think that is a good way of understanding what's happening. You do definitely see it with Japanese imperialism too. Etsuko Taketani talks about this in her book, about the way that Japan was celebrated by many African Americans along the same lines that Ethiopia was celebrated. And if you look at Japanese imperial history, there are a lot of parallels with Ethiopian imperial history and connections between the two empires. I think the latter view that you've presented makes more historical sense to me, that perhaps there's really no space for imagining what it would mean to challenge European imperialism and empire generally as a model.

$A G$ : Yes, it's important to think about the historical specificity of these attachments even as we attend to their limits or contradictions. Shifting gears, I want to talk about forms Imperial Ethiopianism takes. You present three different ways that people articulated and come to shape what this form of attachment to Ethiopia would look like. And in particular, you mentioned a documentary mode, martial mode, and a spectacular mode. I wonder if you could just lay out how these strategies work out in some of the texts. And I think I was really struck also by the ways that, they're not really discrete formations or structures, but they really overlap and inform each other, especially in your discussion of Pauline Hopkins and George Schuyler. I was really interested in how the documentary blends into and informs more spectacular narratives and speculative projects.

$N N$ : I identify three modes of Imperial Ethiopianism in the book. I define "documentary Ethiopianism" as a mode that is literally documenting and attempting to take a fact-based approach to Ethiopia. The second mode I discuss is "martial Ethiopianism," which focuses for the most part on representations of Ethiopian soldiers and battles, and I found it especially prevalent in verse of the period. Finally, "spectacular Ethiopianism" is the term I use to describe the fascination with Ethiopian imperial spectacle, whether in the form of royal costuming, or Orientalist parade, for example. And, yes, it is definitely true that there is a lot of overlap between the categories. In Hopkins's case, for example, I start out by talking about her magazine, the Colored American Magazine, where 
she was the editor, and how the non-fictional texts published there interacted with her novel. What I found was that she ended up using the more documentary mode in talking about actual events in Ethiopia, actual history, actual archeology. She used a lot of travel writing in her novel - and this has been kind of a controversial issue because she essentially plagiarized from texts about African travel to use in her novel — but she infuses it, as you say, with this more speculative mode, imagining a kind of fantasy wherein her characters end up trapped in a pyramid and find this lost city in Ethiopia. I found that these modes of Ethiopianism were really interwoven, where she's both talking about a "Real Ethiopia" but then creating this complete imaginative world that's a precursor to Black Panther's Wakanda, essentially. It's like a proto-Wakanda!

$A G$ : It's really fascinating. And I think it speaks in some ways to where we started the conversation about how this is a moment where Ethiopia as a country is coming into some concretion for the diaspora. There is more information about the place itself that people are engaging with, and this distinguishes it from earlier forms of Ethiopianism, but yet there's still an attachment or investment in its ancientness and in abstraction. There's a certain mysticism around the country. And as we see in your discussion about J.A. Rogers' reporting also for the Courier, there is this constant destabilization of what's fact and fiction about the country, and whose voices count as the authoritative voices on what Ethiopia is and what it can be.

$N N$ : One thing that I thought was really fascinating about J.A. Rogers' reporting in the Courier about Ethiopia was that he kept lapsing into this very fantastic language to talk about what was very concrete for him. Rogers as a journalist had met and interviewed Haile Selassie and covered the conflict extensively. He was not creating this fantasy world of Ethiopia. He had these concrete connections that he could fall back on and yet he ended up falling into this very fantastic way of talking about Ethiopia. That kind of surprised me, but it also ended up being, for me, another example of the overlap between documentary and spectacular Ethiopianism.

$A G$ : One of the ways that spectacularism shows up is through dress and performance. You mentioned the Star Order of Ethiopia early. The group that has a parade in Chicago in 1920 and it opens your book. I've been doing some writing about the Universal Negro Improvement Association and their first convention in 


\section{Adom Getachew}

1920 in New York, which is just a few months after the Star Order of Ethiopia's parade in Chicago. And it just made me think, I wonder if there's some way in which Garvey and Garveyites are very purposefully drawing from that example in some way. So it made me think about the UNIA slightly differently. But, in general one of the strategies for a spectacular Ethiopianism is what you mentioned earlier - these projects of regalization, and especially through the figure of royal impostors in the 1920s. And you write that practices of regalization exhibit "attention between inclusivity (as a universally available fantasy) and exclusivity (as a fantasy that necessarily excludes others from similar exaltation)." So I was really struck by this, the possibility that royalty could be universalized. And I wanted to ask you, how do people universalize or extend royalty, and how does this kind of universalization end up deploying or transforming the kind of necessary exclusivity of royal lineage as well?

$N N$ : I think I had heard about Ethiopian impostors before, about people pretending to be African princes or princesses. It was a phenomenon I was familiar with, but I didn't know that much about it until I read Robert A. Hill's essay about a particular impostor, the Jamaican Isaac Brown, whom I ended up looking into a bit more in my book. And there is, I think, a kind of universal availability of inventiveness. If you can imagine it, you can essentially convince somebody else that it's true. I do talk a little bit about the importance of costume, so perhaps it's not completely true that anybody can invent it-you do need some resources to be able to present yourself as a convincing impostor. But it doesn't need to be Ethiopian costume, as I talk about in that case; it can be anything that signals royalty somehow. I talk about the royal mark as something that can be a sign of royalty that doesn't require a costume. So, if you can show someone a tattoo that suggests that you are royalty, then your presentation is more convincing. But I also mentioned - and this has been pointed out by others - that, in Ethiopia, royalty isn't as connected to genealogy as you might think. An example is Tewodros, who was the son of a woman who allegedly sold kosso - a tapeworm remedy. The Ethiopian impostors became really interesting to me, partly because they aren't completely tied to self-interest, although definitely that's part of it. I wanted to look at what was Ethiopianist about their projects. It wasn't completely about trying to become rich, by pretending to be royalty. There was still some seed of an attempt to foster racial solidarity.

$A G$ : I mean, one of the things that's interesting about some of the impostors is, as 142 
you say, some of them do wear costumes and they invest a lot in the project of looking, obviously, royal. But a lot of them point to something like a mark. And you say that, even when people aren't wearing orientalist costuming, that kind of image is projected onto them. There's a way this shows up in Claude McKay's novel, Amiable with Big Teeth, where there is an instability about who's authentically Ethiopian, because there's one person that's an impostor who does wear orientalist garb and then there is someone who appears to have documentation that suggests that he is in fact, a royal emissary, but doesn't appear, royal, in the ways that people imagine royalty to look. I wondered what you made of the pull of, I don't know what it is, the oriental or the ancient. It also seems to follow how Ethiopia itself as an empire is very invested in this moment in demonstrating its modernity while also holding onto itself as a kind of ancient empire. So I wanted to ask how ideas of a modernizing Ethiopia sat in or alongside this interest in investment in ancientness or representing the orient in a particular way.

$N N$ : I do think that it was very hard to shake the appeal of ancient Ethiopia. That's the basis of Ethiopianism. In one of my chapters, I talk about how a lot of the coverage of Ethiopia, especially of [Haile] Selassie, focused on what was perceived by the media as a kind of contradiction or paradox between the archaic or Biblical versus what I call a "slick" modernity. One of the articles I read-I think it was a Time Magazine article—says that Selassie has the "it factor," which shocked me, to think about that version of modernity as applying to Ethiopia. It was a generalized opposition that I kept seeing in coverage of Ethiopia. It's probably not surprising, for writers and impostors, that this ended up getting absorbed into how they perceived what was happening to Ethiopianism at the time, that there was this uncomfortable juxtaposition of modernity and archaism and that's what Ethiopia represented for them.

$A G$ : And it seems like the duality of simultaneously modern and ancient also follows the concrete v. abstract quality of Ethiopia for those writing or imagining in an Ethiopianist vein. And it's just striking how productive it is for the writers to inhabit the space in between and to play with these categories of mysticism and documentation, modernity and archaism etc. This doubling becomes very productive. For instance, the ancient or archaic depiction shows up is in the chapter on martial Ethiopianism where the poets you cover constantly draw attention to the bare footedness of the Ethiopian soldiers in their fight with Italy in 


\section{Adom Getachew}

the 1930s. I remember this as also a trope I grew up with hearing-that we defeated the Italian army barefooted. And so it's an attempt to magnify in some ways what was achieved in the moment of defeat. It is an exaggerated depiction of the David character in the David and Goliath story. It magnifies the challenge that was overcome. I think it's also again interesting how figures like [Haile] Selassie and Menelik II very knowingly engage or attempt to engage this modern/ancient duality. On the one hand, they want to present themselves as modernizers. You show see this with Menelik II who, as you note, was very interested in adopting modern technologies. He and [Haile] Selassie make a show and a performance of those technologies, but never want to forego the conception of Ethiopia as a biblical or ancient nation. I found that really striking.

$N N$ : I just wanted to add too, that one of the poets that I talk about in the martial Ethiopianism chapter, connects the barefootedness of the soldiers to the soldiers that fought at Valley forge during the war of American independence in the eighteenth century. This kind of mapping onto US history recasts the ItaloEthiopian war as a kind of revolutionary moment.

$A G$ : Very interesting! I think I have maybe a couple more questions for you. First your story comes to end around the second Italian-Ethiopian war. And I wanted to ask you, what becomes of Ethiopianism after the war? And if you were to continue the story after, where do you think you might have gone with it?

NH: I end by talking about Langston Hughes' visit to Ethiopia in my conclusion, which was in 1966, and I argue that it represents a decisive turn at least among African American writers when it is not really sustainable anymore in the midst of Africa's decolonization to really look at Ethiopia as a kind of model. And he's really disgusted with his reception by Selassie, feeling like it's inappropriate to flaunt this kind of imperial culture. When he goes to meet him, he's told that he should dress in a particular way. And he tells his aunt, "Who does he think he is to make me dress up just to get an award?" or something like that. And she says to him, "Well, would you have said that about visiting the Queen of England?," to which Hughes says that Selassie wasn't born European. For him that's essentially what the moment felt like, like he was being presented to European royalty and he's surprised by that. So it seemed to me that after mid-century, it's not really sustainable, as I said, to hold up a kind of Ethiopianism like the one that is used throughout the late 19th and early 20 th centuries. 
$A G$ : I think it speaks in some ways to what we were saying earlier about how the period you're writing about, from the late $19^{\text {th }}$ century to the 1940 s, is a period where there isn't really an imagination outside of empire as a counterpoint to empire. But in the postwar period, there's all these alternatives. There's all these nations gaining independence, there is the civil rights movement, Ethiopia itself is on the precipice of revolution. My last question is about how that Langston Hughes' story opens another possibility of thinking about Ethiopianism. You highlight his friendship with Tsegay Gebre Medhin, the Ethiopian poet and playwright and read their friendship as one possible alternative model to the kind of hierarchical vision of imperial Ethiopianism. There's another moment too, where there seems like a different possibility of identification. This is actually an instance where solidarity actually occurs through through dis-identification. And that's through the character of Bill in Schuyler's Revolt of Ethiopia. Bill who has no pretensions of royalty and is quite distant from Ethiopianism ends up becoming the hero in the story. I wonder if you can just tell us a little bit about these two possibilities that remain kind a minor key of your narrative?

$N N$ : Yeah. I think the character in Schuyler's novella is interesting to me partly because he is minor. He does kind of save the day, and in some ways is the hero, but he is the valet of the protagonist and he's definitely a minor character in the scope of the novella. But he's able to save the day by passing a message to an Ethiopian woman that is a kind of lateral communication. So, even though the character has no investment in Ethiopianism, the note stands in for a way of imagining Ethiopianism that doesn't have to go through monarchy in the way that, for example, Pauline Hopkins' model did. When Pauline Hopkins is imagining connections between the old and the new world, it is because Reuel, the main character of her novel, goes back to Ethiopia and discovers he's actually the King. It's not like he can just go back and find that he's related to somebody there. He ends up having to be the King. I started to see traces of a more egalitarian Ethiopianism in Schuyler, but it wasn't until, as you point out, the development of that real life connection between Langston Hughes and his translator Tsegay Gebre Medhin that this possibility comes into fruition. You begin to see particular connections between writers. And that to me is the potential direction for Ethiopianism that is beyond the scope of the book. That seems like where it might go if the narrative arc of the book were to continue.

AG: Thank you Nadia! Those were my questions. I guess maybe I'll just invite 
you to share what you are working on next.

$N N$ : I have been starting to think about a new project that will involve Harry Dean, who was one of the writers I talk about in this book. I did the same thing between my first and second books where I was writing quite a bit about Paul Laurence Dunbar in first book, and then he kind of jumped to the second book. And now I'm thinking about Harry Dean a bit more and starting to write an article that might be the beginnings of a third book, I'm not sure. I'd also like to do a critical edition of Harry Dean's book because it's not available. And I think it's a really important book, to be honest-it's a memoir about his attempt to, as he puts it, "Found an Ethiopian empire." That's my plan for my next project.

$A G$ : That sounds great. Thank you so much for doing this.

$N N$ : Thank you, really, for this conversation.

Bios:

Nadia Nurhussein is Associate Professor in English and Africana Studies, specializing in African American literature and culture. She is the author of Black Land: Imperial Ethiopianism and African America (Princeton University Press, 2019) and Rhetorics of Literacy: The Cultivation of American Dialect Poetry (The Ohio State University Press, 2013). Prior to arriving at Johns Hopkins, Prof. Nurhussein taught in the English departments at the University of Massachusetts, Boston, from 2005 to 2016 and at Mount Holyoke College from 2004 to 2005. In 2004, she earned her PhD in English at the University of California, Berkeley. She has received fellowships from the Ford Foundation, the Beinecke Library at Yale University, and the American Council of Learned Societies.

Adom Getachew is Neubauer Family Assistant Professor and the College of the University of Chicago. She is a political theorist with research interests in the history of political thought, theories of race and empire, and postcolonial political theory. Her work focuses on the intellectual and political histories of Africa and the Caribbean. She is the author of Worldmaking After Empire: The Rise and Fall of Self-Determination. 